\title{
The future of hospital quality of care policy: A multi-stakeholder discrete choice experiment in Flanders, Belgium
}

\author{
Jonas Brouwers ${ }^{\mathrm{a}, \mathrm{b}, *}$, Bianca Cox ${ }^{\mathrm{a}}$, Astrid Van Wilder ${ }^{\mathrm{a}}$, Fien Claessens ${ }^{\mathrm{a}}$, Luk Bruyneel ${ }^{\mathrm{a}}$, \\ Dirk De Ridder ${ }^{\mathrm{a}, \mathrm{c}}$, Kristof Eeckloo ${ }^{\mathrm{d}, \mathrm{e}}$, Kris Vanhaecht ${ }^{\mathrm{a}, \mathrm{c}}$ \\ ${ }^{a}$ Leuven Institute for Healthcare Policy, KU Leuven - University of Leuven, Belgium \\ ${ }^{\mathrm{b}}$ Department of Orthopaedics, University Hospitals Leuven, Belgium \\ ' Department of Quality Improvement, University Hospitals Leuven, Belgium \\ ${ }^{\mathrm{d}}$ Department of Primary Care and Public Health, Ghent University, Belgium \\ e Strategic Policy Unit, Ghent University Hospital, Belgium
}

\section{A R T I C L E I N F O}

\section{Article history:}

Received 11 April 2021

Revised 4 September 2021

Accepted 10 October 2021

Available online $\mathrm{xxx}$

\section{Keywords:}

Hospital

Quality of healthcare

Health policy

\begin{abstract}
A B S T R A C T
Background: Collaboration between policymakers, patients and healthcare workers in hospital quality of care policy setting can improve the integration of new initiatives. The aim of this study was to quantify preferences for various characteristics of a future quality policy in a broad group of stakeholders.

Materials and methods: 450 policymakers, clinicians, nurses, patient representatives and hospital board members in Flanders (Belgium) participated in five discrete choice experiments (DCE) on quality control, quality improvement, inspection, patient incidents and transparency. For each DCE, various attributes and levels were defined from a literature review and interviews with 12 international quality and patient safety experts.

Results: For the attributes with the highest relative importance, participants exhibited a strong preference for quality control by an independent national organization and coordination of quality improvement initiatives at the level of hospital networks. The individual hospital was chosen over the government for setting up an action plan following patient complaints. Respondents also strongly preferred mandatory reporting of severe patient incidents and transparency by publicly reporting quality indicators at the hospital level.
\end{abstract}

Conclusions: A future quality model should focus on a multicomponent approach with external quality control, improvement actions on hospital network level and public transparency. DCEs provide an opportunity to incorporate the attitudes and views for individual components of a new policy recommendation.

(c) 2021 Elsevier B.V. All rights reserved.

\section{Introduction}

Governments worldwide struggle to find models for their healthcare systems that ensure the quality of care delivered to patients. In the past twenty years, different external quality control mechanisms were implemented and tried in many European countries ranging from accreditation of hospitals to compliance with ISO-norms as identified by the European research project on external peer review mechanisms (ExPeRT) [1,2]. Quality of care policy in hospitals is often decided by policymakers and hospital managers with less incorporation of stakeholders' opinion and thus creating an "accountability gap" between healthcare providers

\footnotetext{
* Corresponding author.

E-mail address: jonas.brouwers@kuleuven.be (J. Brouwers).
}

on the one hand and patients, financiers and governments on the other [1]. Healthcare workers often feel disconnected to decisions taken above their head and they feel like quality initiatives are imposed on them. Nevertheless, promising evidence exists to incorporate bottom-up initiatives for sustainable quality improvement policy [3]. Therefore, to establish broadly supported quality models for hospitals, policymakers should also incorporate the views of stakeholders such as healthcare workers and patient representatives [4]. Various strategies are now employed to tackle quality concerns in our healthcare services but the cost-effectiveness is not always demonstrated [5-8]. An example is the external accreditation of hospitals, which has been implemented as a quality control mechanism in many European countries to ensure the safety of care processes and patients. Studies suggest that accreditation has promoted change and professional development but 
also involved substantial financial costs, staff time and other resources $[9,10]$. Many countries have also implemented other quality initiatives such as visitation by clinical peers, public reporting of quality indicators, government inspection or incident reporting systems [1,11]. Different voices raised concern about the possible negative impact on patient outcomes by risk aversive behavior by physicians [12] or gaming of data [13] with public reporting. Also, the growing gap between paper-based initiatives and the reality of clinical practice questioned the continuation of certain initiatives $[14,15]$. During recent years, criticism has been raised regarding the administrative burden [9,16], excessive demands [17,18] and the reduced attention for patients $[19,20]$ associated with many quality initiatives. As a result, some hospitals started to withdraw from these quality efforts and rethink their quality of care policy [21-24]. Limited data exist on the effect of healthcare worker's attitude towards accreditation [17,18,25], but is not available for other quality efforts. Nevertheless, a positive attitude of healthcare staff towards quality improvement initiatives is a key factor for their successful implementation [25,26] and agreement between stakeholders is an essential part for broadly supported policy reforms.

The aim of this study was to quantify healthcare workers', policymakers' and patient representatives' preferences for various characteristics of future quality of care initiatives on policy (macro) and hospital management (micro) level in Flanders, Belgium. For this purpose, we used a discrete choice experiment (DCE) which is extensively used in medical and health services literature [2730] but, to the best of our knowledge, has not yet been applied to elicit preferences for general quality of care policy questions.

\section{Materials and methods}

\subsection{Setting}

In Flanders, the northern region of Belgium with 6.6 million inhabitants, the regional government introduced a 'Quality of care triad' in 2009, consisting of voluntary participation in hospitalwide external accreditation, mandatory government inspections and public reporting of quality indicators. A full overview of the Flemish quality of care approach is provided by Van Wilder et al. [31]. Recently, some Flemish hospitals have withdrawn from external accreditation and started thinking about a new approach for future quality of care processes, with involvement of their healthcare workers. The hospital umbrella organization (Zorgnet-Icuro) and the government intend to start negotiations on new quality policy reforms based on evidence-based research and involvement of all relevant stakeholders.

\section{2. $D C E$}

A DCE is a stated choice exercise that can quantitatively assess people's choices in different scenarios [32-36]. Unlike ranking or rating methods, DCEs force respondents to make trade-offs, thereby providing insight into the relative importance of the questioned attributes (characteristics of the quality initiatives in this case). A DCE has theoretical grounds in the random utility theory and can establish preferences in controlled experimental conditions through responses to realistic and hypothetical screening scenarios, composed of their characteristics (attributes) which are specified by variants of those attributes (levels). A DCE is constructed by systematically varying attribute levels to generate a set of screening modalities. In each choice task, respondents will choose their most favorable scenario between a number of competing scenarios. By changing the attribute levels repeatedly, preferences for different attributes and levels can be estimated [37].

\subsection{Selection of attributes and levels}

We selected the attributes and levels by applying an extensive framework $[37,38]$ for the development of a DCE. We started with a literature review including policy reports and peer reviewed articles published between 2000 and 2020 concerning quality of care guided by the Donabedian framework [6,39-44]. Interviews with 12 experts from various international institutes (ISQUA, OECD, IHI 2x, EHMA, NIVEL) and countries (USA, Sweden, Denmark, Italy, Australia, Netherlands) were performed to identify facilitators and barriers in the current Flemish model for hospital quality of care and give recommendations for future policy plans. This led to the development of five individual DCE experiments on the following topics: quality control, quality improvement, inspection, patient incidents, and transparency of results. Feedback on attributes and attribute levels was given by a stakeholder group $(n=33)$ consisting of patient representatives, quality managers, government representatives, physicians, hospital board members and medical directors. Based on this feedback, a group of five quality experts from our research group narrowed down the list of attributes and levels. According to good practices for DCE research [45,46], the final number of attributes per DCE ranged from three to five and the number of levels per attribute from two to four and most of the attribute levels were nominal variables (Table 1). A pilot test of the DCE was performed among 10 randomly invited persons (nurses, doctors, patients and quality experts) resulting in some minor adaptations to exclude unrealistic attribute-level combinations that could discourage respondents

\subsection{Experimental design of the choice sets}

We used Sawtooth Software (Lighthouse Studio V.9.9.1) to create the 5 DCEs, using the balanced level overlap method and Doptimal procedures to maximize statistical efficiency [47]. For each DCE, 300 survey versions were automatically made with the number of random choice tasks per DCE ranging from 5 to 10. For each choice task, the respondent was asked to choose one situation out of four alternatives (exemplified in supplemental figure 1). The estimated minimum sample size required to achieve an acceptable level of statistical precision was 300 respondents [48-50].

\subsection{Survey administration}

Hospital board members, clinicians (physicians and nurses), staff members and supervisors, policymakers and patients (staff members of the Flemish Patient Association (VPP)) were invited to participate in the online survey. The survey was disseminated with a general link by the hospital umbrella organization Zorgnet-Icuro, the Flemish hospital network KU Leuven (VznkuL), and the Leuven Institute for Healthcare Policy (LIHP). The survey was available for respondents between July 16 and September 3 2020,. The survey also included questions on sociodemographics (profession, working experience, region of working place, type of hospital...). All respondents read the project information and provided online consent to take part before starting the online survey. A multistakeholder steering committee was brought together to give feedback and discuss the results of the survey and analyses in February 2021. This steering committee existed of 33 representatives of the umbrella hospital organization (Zorgnet-Icuro), the government, patient organizations, physicians, hospital board members, quality managers and medical directors. Subsequent negotiations with the government to shape and re-calibrate the current Flemish quality of care policy took place based on the results of this DCE. 
Table 1

Attributes and levels of the 5 discrete choice experiments.

\begin{tabular}{|c|c|c|}
\hline DCE topic & Attribute & Level \\
\hline \multirow[t]{11}{*}{ Quality control } & Control by & $\begin{array}{l}\text { Hospital itself } \\
\text { The government } \\
\text { Independent national/Flemish organization } \\
\text { Independent international organization }\end{array}$ \\
\hline & \multirow[t]{2}{*}{ Announced control } & Yes \\
\hline & & No \\
\hline & \multirow[t]{4}{*}{ Control at the level of } & Department \\
\hline & & Care trajectory \\
\hline & & Hospital \\
\hline & & Loco-regional hospital network \\
\hline & Transparency results & $\begin{array}{l}\text { Only internally in the hospital and/or network } \\
\text { Public website }\end{array}$ \\
\hline & \multirow[t]{3}{*}{ Improvement trajectory based on } & External audit results \\
\hline & & Complaints \\
\hline & & Internal quality measurements \\
\hline \multirow[t]{12}{*}{ Quality improvement } & \multirow[t]{3}{*}{ Coordination of initiatives by } & Loco-regional hospital network \\
\hline & & Individual hospital \\
\hline & & Discipline-specific scientific organization \\
\hline & \multirow[t]{3}{*}{ Financial incentive for quality } & At hospital level \\
\hline & & At individual caregiver level \\
\hline & & No financial compensation \\
\hline & \multirow[t]{3}{*}{ Quality education } & Mandatory for all hospital employees \\
\hline & & Not mandatory for all hospital employees \\
\hline & & Only for hospital quality staff \\
\hline & \multirow[t]{3}{*}{ Comparison of quality results } & Between nationally comparable hospitals \\
\hline & & Between internationally comparable hospitals \\
\hline & & Between all hospitals \\
\hline \multirow[t]{6}{*}{ Inspection } & \multirow{2}{*}{ Patient complaints are followed by an action plan by } & The government \\
\hline & & The individual hospital \\
\hline & \multirow{2}{*}{ Wellbeing of employees is surveyed by } & The government \\
\hline & & The individual hospital \\
\hline & \multirow[t]{2}{*}{ The government inspects basic conditions, organization and results } & Of the hospital as a whole \\
\hline & & Of certain care trajectories within the hospital \\
\hline \multirow[t]{8}{*}{ Patient incidents } & \multirow[t]{2}{*}{ Reporting of severe incidents } & Mandatory \\
\hline & & Not mandatory \\
\hline & \multirow[t]{2}{*}{ Detection } & Through personal reporting by employees \\
\hline & & Through validated tools \\
\hline & \multirow[t]{2}{*}{ Reported to } & The hospital internally \\
\hline & & A central agency or government \\
\hline & \multirow{2}{*}{ Numbers of incident reports } & Publicly available each year \\
\hline & & Only available for the individual hospital \\
\hline \multirow[t]{8}{*}{ Transparency } & \multirow[t]{2}{*}{ What to report } & Hospital-wide indicators (e.g. mortality, readmissions...) \\
\hline & & Disease-specific indicators \\
\hline & \multirow[t]{3}{*}{ Collection of data } & At individual patient level \\
\hline & & At department level \\
\hline & & At hospital level \\
\hline & \multirow[t]{3}{*}{ Public reporting of quality indicators } & At individual caregiver level \\
\hline & & At department level \\
\hline & & At hospital level \\
\hline
\end{tabular}

\subsection{Model estimation}

The DCE results were analysed through the Hierarchical Bayesian (HB) method for choice-based conjoint analysis in Sawtooth software [51], using the default settings and including profession as a covariate. At the lower level of the two-level HB model, the coefficients of individual respondents are estimated through multinomial logit, and at the upper level information among respondents is shared through multivariate normal methods. Parameters are estimated using the Metropolis-Hasting algorithm, a type of Markov chain Monte Carlo iterative procedure. Results are presented as the mean zero-centered part-worth utilities across respondents and can be interpreted as the attractiveness of each level within the attribute [46]. We also estimated the mean importance of attributes across respondents, reflecting the effect (importance) of the attribute in the choice decision. In a secondary analysis, we obtained mean part-worth utilities and importance by profession groups. In sensitivity analyses, we assessed robustness of results by excluding fast respondents, and by restricting the analyses to those that completed the five DCEs. A respondent was con- sidered as fast when his/her total survey time up to the last page completed was lower than the 10th percentile of the cumulative time distribution up to that page.

\section{Results}

\subsection{Sample}

After dissemination, 601 surveys were returned, of which 20 were excluded because they could not be categorized within an established professional group. A total of 131 respondents filled in the demographic questions but did not complete any choice task, resulting in a final sample size of 450 . Of these respondents, $15(3.3 \%)$ were government officials, 72 (16\%) were hospital board members, 187 (41.6\%) were staff members and supervisors, 165 (36.7\%) were clinicians and $11(2.4 \%)$ were staff members of the Flemish Patient Association (hereafter referred to as patient representatives). Almost half $(45.1 \%)$ of the respondents had more than 10 years of working experience in their current job, whereas the 
Table 2

Sociodemographic characteristics of respondents $(N=450)$.

\begin{tabular}{|c|c|}
\hline Characteristics & Number (\%) \\
\hline \multicolumn{2}{|l|}{ Profession } \\
\hline Government officials & $15(3.3)$ \\
\hline Hospital board members & $72(16)$ \\
\hline Staff members and supervisors & $187(41.6)$ \\
\hline Clinicians & $165(36.7)$ \\
\hline Patient representatives & $11(2.4)$ \\
\hline \multicolumn{2}{|c|}{ Working experience in current job } \\
\hline$<5$ years & $137(30.4)$ \\
\hline $5-10$ years & $110(24.4)$ \\
\hline$>10$ years & $203(45.1)$ \\
\hline \multicolumn{2}{|l|}{ Region of working place } \\
\hline Flemish-Brabant & $108(24)$ \\
\hline Antwerp & $92(20.4)$ \\
\hline East-Flanders & $76(16.9)$ \\
\hline West-Flanders & $83(18.4)$ \\
\hline Limburg & $54(12)$ \\
\hline Brussels & $34(7.6)$ \\
\hline Wallonia & $0(0)$ \\
\hline Netherlands & $3(0.7)$ \\
\hline \multicolumn{2}{|l|}{ Type of hospital* } \\
\hline University hospital & $106(26.4)$ \\
\hline Regional hospital & $296(73.6)$ \\
\hline \multicolumn{2}{|c|}{ Number of recognized beds in hospital ${ }^{* *}$} \\
\hline$<500$ beds & $145(35.5)$ \\
\hline $500-1000$ beds & $134(32.8)$ \\
\hline$>1000$ beds & $121(29.6)$ \\
\hline I don't know & $9(2.2)$ \\
\hline \multicolumn{2}{|l|}{ Accredited hospital ${ }^{*}$} \\
\hline Yes, by JCI & $222(55.2)$ \\
\hline Yes, by NIAZ & $164(40.8)$ \\
\hline No & $14(3.5)$ \\
\hline I Don't know & $2(0.5)$ \\
\hline \multicolumn{2}{|l|}{ Times accredited ${ }^{* * *}$} \\
\hline $1 \mathrm{x}$ & $224(58)$ \\
\hline $2 \mathrm{x}$ & $61(15.8)$ \\
\hline More than $2 \mathrm{x}$ & $87(22.5)$ \\
\hline I don't know & $14(3.6)$ \\
\hline
\end{tabular}

other half had less than 5 years (30.4\%) or 5 to 10 years (24.4\%) of working experience (Table 2).

\subsection{Main analysis}

DCE-specific analyses included all respondents that completed that DCE, i.e. 450 (quality control), 379 (quality improvement), 362 (inspection), 358 (patient incidents), and 356 (transparency) respondents respectively.

Fig. 1 panels $A$ to $E$ show the estimated importance and partworth utilities for the five DCEs. Attributes are ordered by descending importance and levels by descending part-worth utility. In the quality control DCE (panel A), "control by" was the attribute with the greatest relative importance on respondents' choices (36.6\%), followed by "improvement trajectories based on" (24.7\%). Of the levels, control by "an independent national/Flemish organization" had the highest (positive) attractiveness (most preferred) and control by "the hospital itself" the lowest (negative) attractiveness (least preferred). Improvement trajectories based on "internal quality measurements" and "external audit results" were approximately equally preferred (overlapping confidence intervals) and were more attractive than improvement trajectories based on "complaints". Relative importance of the other 3 attributes were lower $(<15 \%)$. Control at the level of the "hospital" was most preferred and at the level of the "department" least preferred, whereas respondents did not seem to have distinct preferences for the remaining two attribute levels (part-worth utilities not significantly different from zero). "Unannounced quality control" and "transparency of quality control results on a public website" scored better than "announced control" and "transparency limited to hospital- or network-level", respectively.

The same visualizations are made for the other DCE topics as shown in panel B to E. Coordination of quality improvement initiatives by "a loco-regional hospital network" was preferred over "discipline specific scientific organizations" or "individual hospitals" and education in quality of care was chosen to be "mandatory for all hospital employees" (panel B). Patients' complaints should be followed by an action plan "by the individual hospital" rather than "by the government" amongst most of the respondents. There was no distinct preference for one of the levels of the attribute "government inspects structure indicators" ("of the hospital as a whole" versus "certain care trajectories within the hospital") as seen in panel C. Reporting of severe patient incidents is chosen to be "mandatory" (attribute importance of $40.8 \%$ ). Other attributes were less important $(24.6 \%, 19.1 \%, 15.5 \%)$ and preferences for their levels is shown in panel D. Finally, as seen in panel E, "public reporting of quality indicators" was the most important attribute (53\%) with highest preference for "reporting at hospital level". If asked about "what to report", respondents preferred "disease specific indicators" and collection of data at "department level".

\subsection{Secondary and sensitivity analyses}

Results by profession are presented in supplemental figure 2 panels A to E. Relative importance and part-worth utilities were quite similar between groups, except for some differences observed for patient representatives and government officials.

Results from sensitivity analyses (excluding fast respondents and excluding those that did not complete all five DCEs) were similar to those from the main analysis (supplemental figures $3 \mathrm{~A}-\mathrm{E}$ ).

\section{Discussion}

This study provides a novel approach for policy setting in healthcare quality reforms. It is the first attempt to include stakeholders' views by the use of discrete choice experiments for different quality of care topics. The importance of involvement of stakeholders in policy setting discussions in our hospitals has been highlighted for years $[4,52,53]$. The results of this research show a preference (high part-worth utilities within attributes) of participants towards quality control by an independent national organization rather than international organizations or the government itself. This trend is also seen in other countries as more and more hospitals withdraw from international accreditation systems $[24,31,54]$. Hospital employees, for example, have raised the concern that standards of international accreditation organizations are not always appropriate for specific local circumstances and they feel disconnected with this imposed control mechanism. The paucity of high-quality controlled evaluations of external inspection systems, the need for more explicit values and customer adaptations but also the heavy bureaucracy are seen as extra reasons for this trend of withdrawal [4,55].

Quality improvement initiatives on regional hospital network level are preferred by respondents in our sample. Although quality improvement initiatives on more local level, like clinical pathways $[56,57]$, are standard practice, a recent policy reform in Flanders installed different hospital networks whereby hospitals will need to work together to centralize certain pathologies and supporting services like the hospital pharmacy and laboratory. This could be the reason that respondents in this sample tend more towards quality improvement on network level rather than to keep it on individual hospital level. 

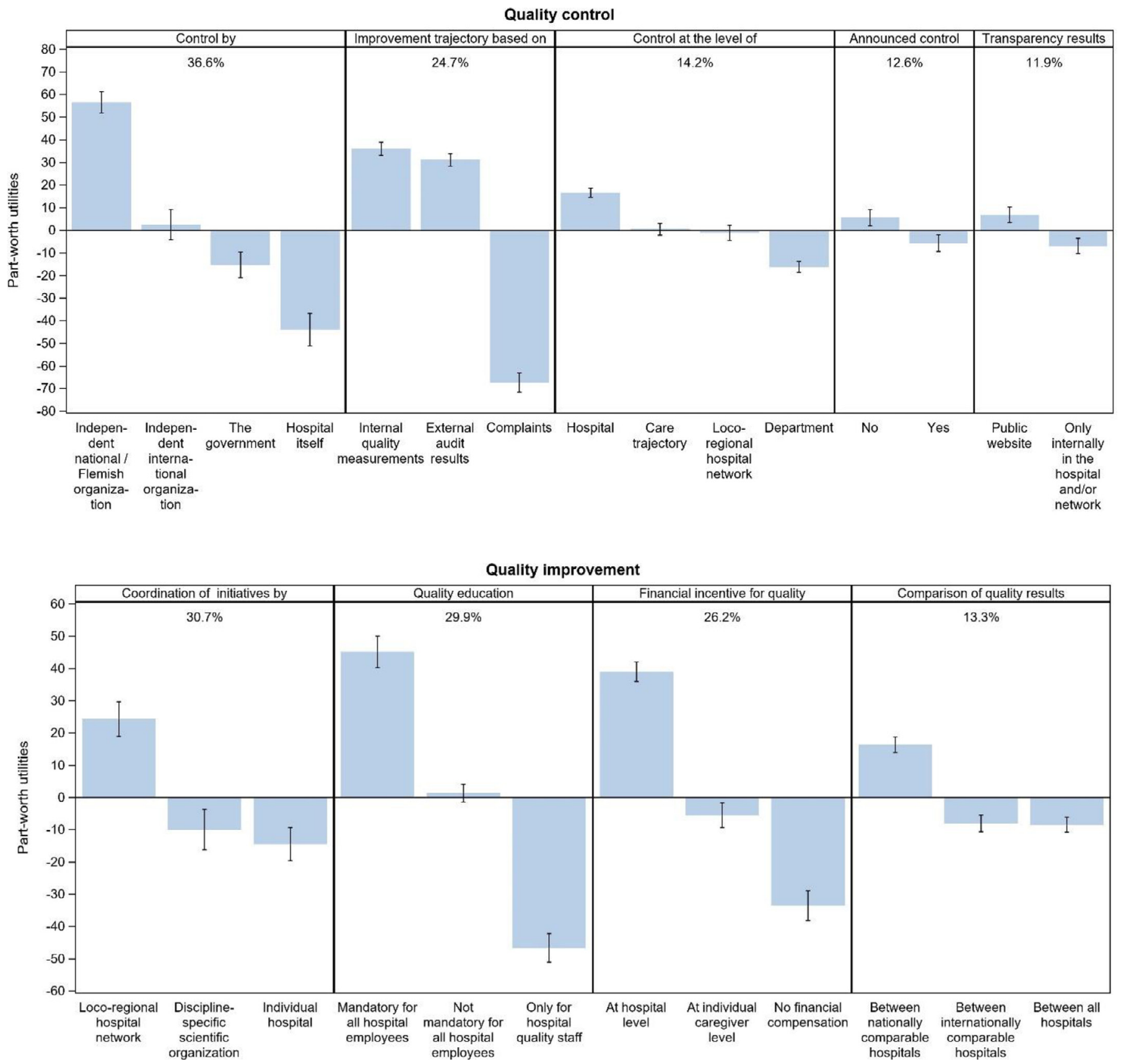

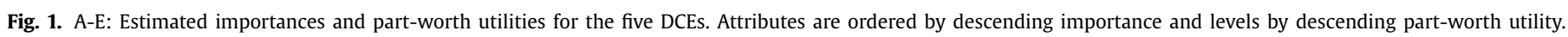

The other discrete choice experiments are in line with international trends as we see that reporting of patient incidents is already mandatory in many countries [58-60]. Until now, in the Flemish healthcare setting, incident reporting is not yet mandatory and these results urge policymakers to rethink this choice. The public transparency of quality indicators on hospital level is also key for a healthcare quality policy as it stimulates quality improvement activities and alters hospital selection by the patient $[31,61]$. Government agencies, including the Agency for Healthcare Research and Quality (AHRQ) and the Institute of Medicine (IOM), and the European ExPeRT program have emphasized that public availability of hospital quality information is integral to a longterm strategy to improve healthcare for patients [2,62,63]. Public reporting of data on quality of healthcare in Flanders currently encompasses the publication of hospital-level process and outcome indicators by a governmental agency. Results of our study indicate a positive attitude towards more detailed reporting of diseasespecific quality indicators collected at department level. On the other hand, respondents showed a strong preference for reporting at hospital or department level instead of at individual caregiver level, which may be linked to the expected risk-averse behavior or other issues associated with physician-level reporting [64,65]. Although globally, questions are raised about the effectiveness of public reporting on patient outcomes [66,67], the importance to incorporate this in future policy is well demonstrated in this DCE. Finally, patient complaints are an important topic for hospitals because it provides areas of concern and a basis for quality improvement projects. Our DCE shows that respondents prefer to link these complaints to action plans by an individual hospital which corresponds with trends seen internationally $[68,69]$. 
Inspection

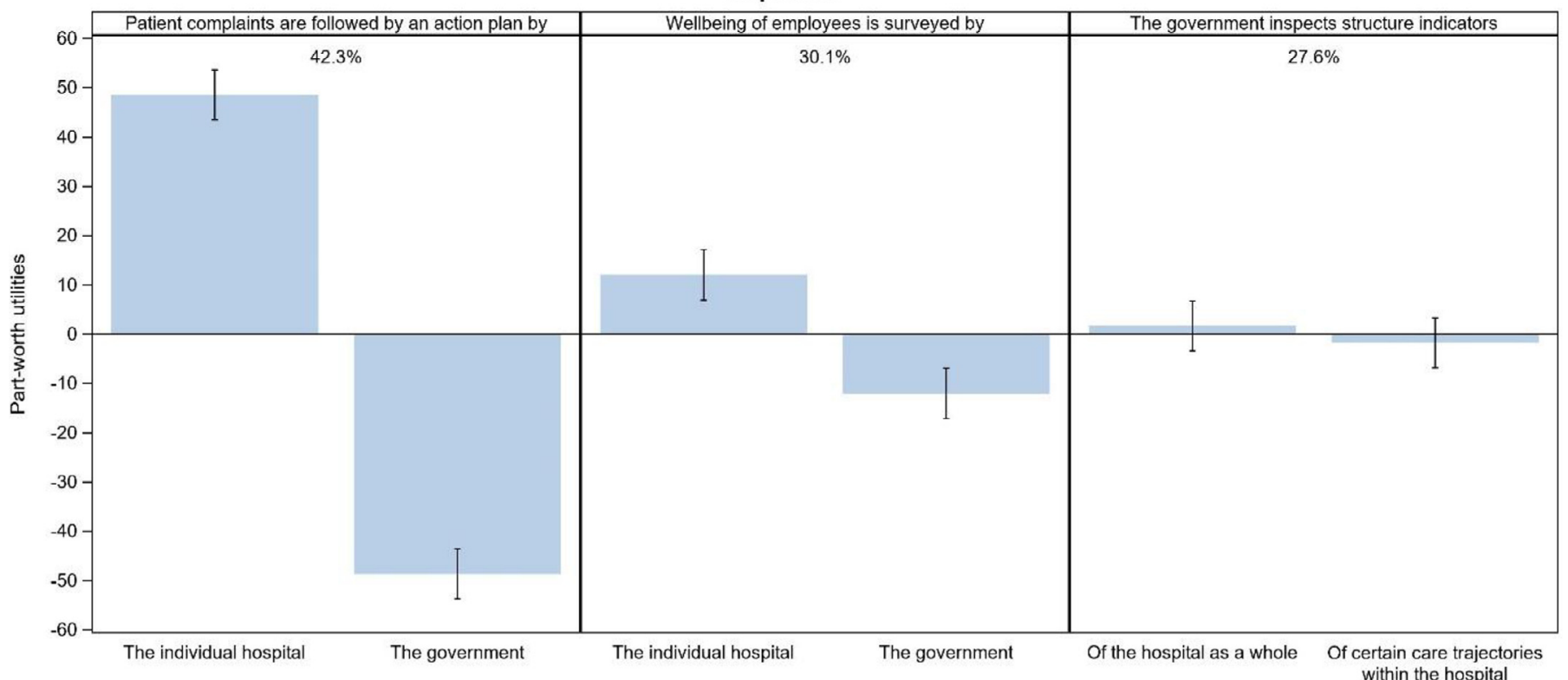

Patient incidents

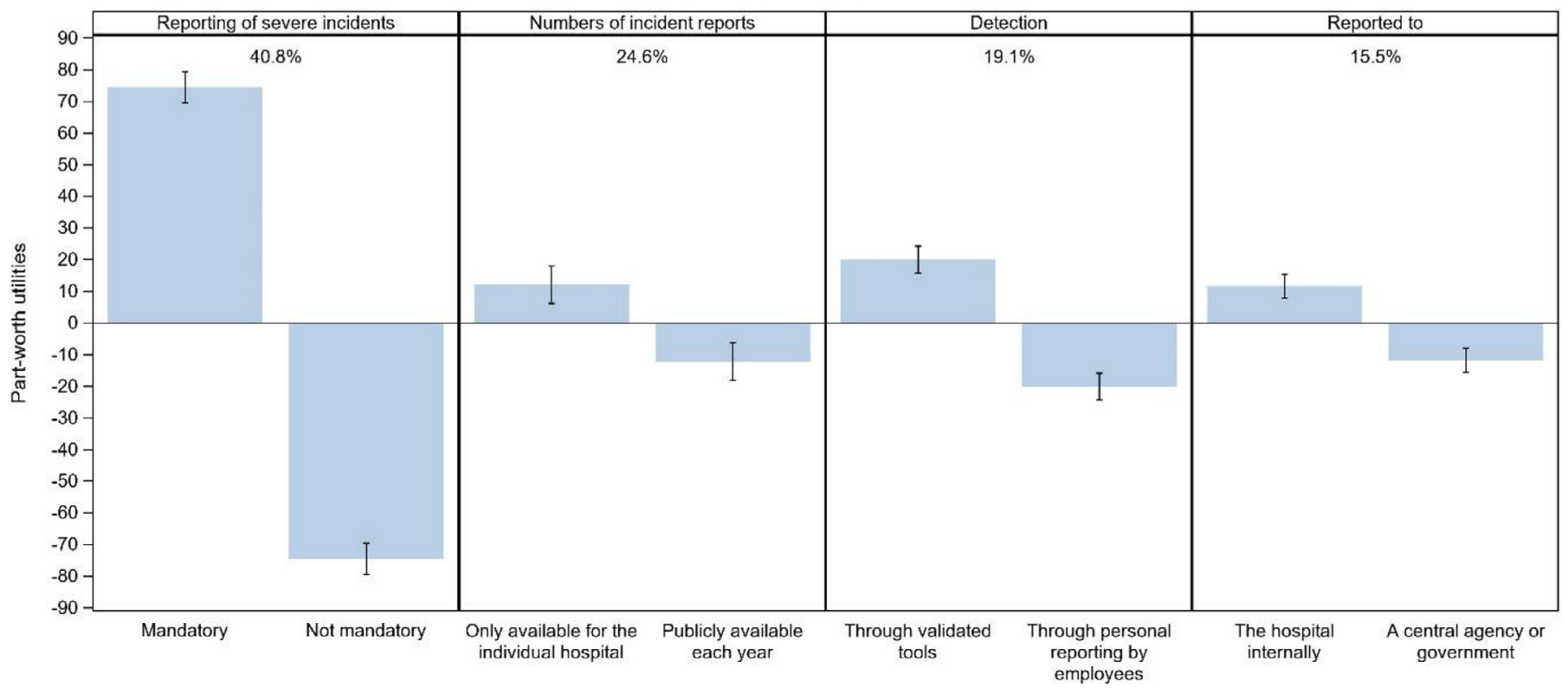

Fig. 1. Continued

Overall, the results of these DCE topics provides the basis for policy reforms in a local Flemish context. As many of the respondents' preferences in these topics are also seen internationally, the convergence of quality improvement programs is possible as was also emphasized as a working point by the European ExPeRT project. It is the duty of policymakers to consider the input they receive of different sources for their policy choices. An extensive discrete choice experiment can be one of the ways to use the voice of stakeholders for new frameworks, but just as important are international trends and good practices as demonstrated above. This research does not aim to give an exhaustive list of mandatory policy reforms but rather presents a good basis for future discussions. Different quality ideas in our DCE that are not yet implemented in Flanders (like mandatory reporting of severe patient incidents and hospital-wide action plans following patient complaints) suggest that participants are open to new quality of care initiatives.
It is therefore recommendable to use their voice and enthusiasm for the construction of a new quality of care model in Flanders. Although, to our knowledge, multi-criteria decision tools have not yet been applied in the context of quality of care policy, they have proven to be useful for eliciting preferences in health services utilization [70-74] and DCEs are increasingly used in priority setting for medical interventions and clinical issues. Rational approaches to guide decisions are desirable and a more formalized and explicit way to include different views may improve the policy process $[75,76]$. DCEs can be one of the methods to meet these demands for healthcare policy settings. Although the scenarios used in the DCEs are hypothetical, they are effective in approximating real-world decisions rather than just ranking or rating single characteristics [77]. Despite the time-consuming and cognitively challenging aspect to DCEs, a commendable number of respondents $(N=356)$ completed the entire survey, possibly indicating the im- 


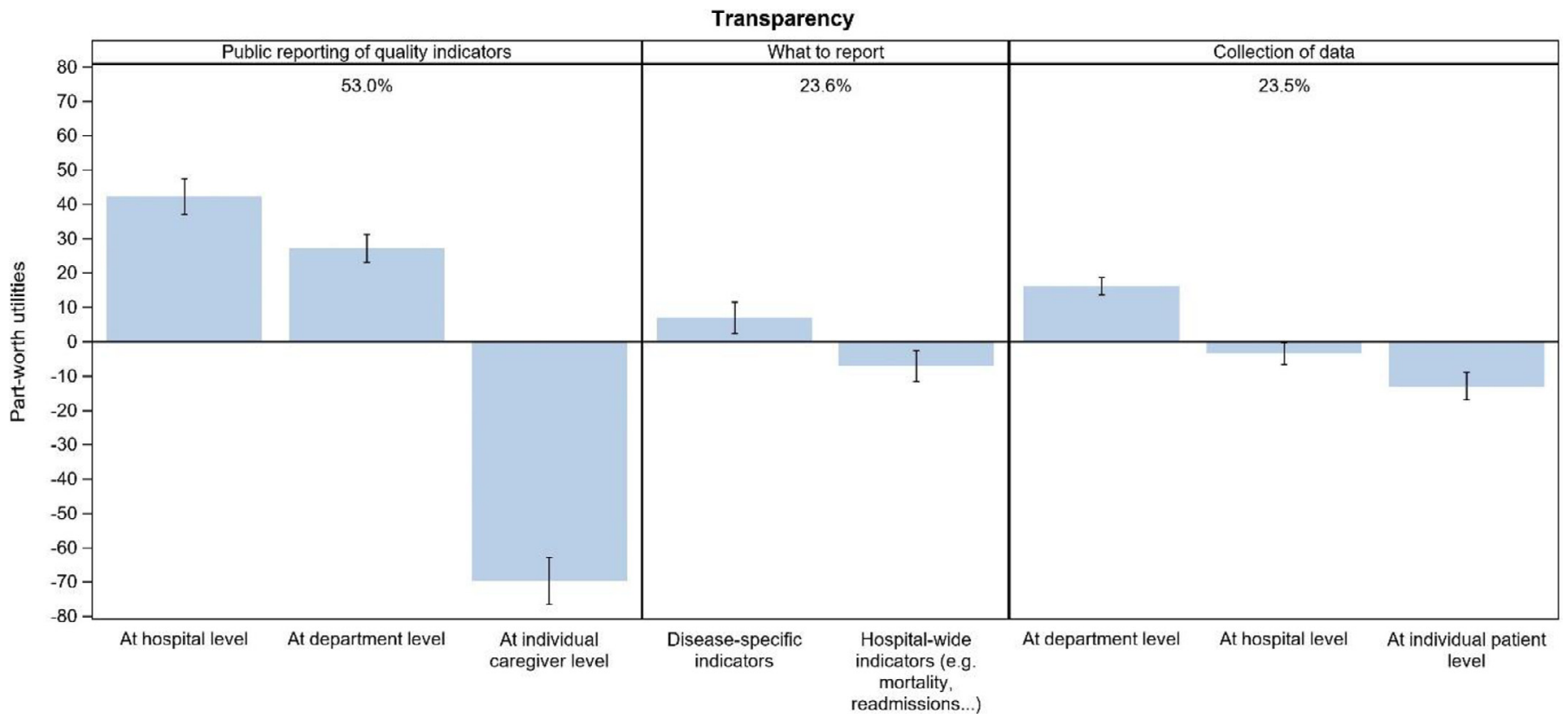

Fig. 1. Continued

portance they attach to the research questions. The settings of the DCEs were built around a current Flemish quality of care approach but can be easily adapted for other international contexts. This can help to shape systems to local situations and aid governments to implement specific quality of care reforms and frameworks.

This study has a number of limitations. First, the generalizability of profession-specific results can be questioned due to the low number of respondents in some groups (patient and governmental representatives). Nevertheless, the numbers for clinicians, staff members and hospital board members were high and the use of a DCE to hear their voices is on itself already a very useful initiative. We therefore did not go deeper into the profession-specific results in this paper. Second, the time burden and cognitive challenge associated with filling in five DCE exercises could be a limitation for consistency of our results. Yet, sensitivity analyses showed good internal validity of the DCEs and 356 respondents completed the whole questionnaire till the end. Third, this study design employed a main-effects model, the most commonly used approach in healthcare-related DCEs [34], which assumes the absence of attribute interactions [78]. Although this study was pilot tested to identify and remove attributes that were seen as highly correlated, the possibility of bias introduced by correlation between these attributes cannot be excluded. Lastly, although this study is built around five separate DCE scenarios, its aim is to give a multi-topic approach for policymakers to make supported decisions in their policy plans. We are aware that the relative (perceived) importance of each DCE topic itself is not assessed, as this is inevitable in the design of this study. We could impossibly make a DCE design concerning all five topics at once, because this would lead to an uncountable number of attribute-level combinations and analyses would not be possible. Nevertheless, each DCE topic on itself provides useful information for policymakers and governments to start their process of policy reforms.

\section{Conclusion}

The choice for future quality of care initiatives is an important challenge to tackle and policymakers should consider stakeholders' preferences to ensure support in the field. This research attempted to provide a better understanding of healthcare workers', government officials' and patient representatives' perspectives towards future quality of care policy by the use of DCEs in a Flemish context. Among these stakeholders, future policy reforms should focus on quality control by an independent national organization and coordination of quality initiatives on hospital network level. Patient complaints should be followed by an action plan by an individual hospital and reporting of incidents should be mandatory. This study also showed that public reporting of quality indicators at individual caregiver level is not preferred among healthcare workers. DCEs can be a promising instrument for assessing attitudes towards various aspects of quality of care and they can serve as an intermediary step in creating new policy reforms. Policymakers will need to continue discussions with relevant stakeholders and make further choices based on their opinions, international good practices and proven evidence of new quality of care models.

\section{Declarations of Interest}

None.

\section{CRediT authorship contribution statement}

Jonas Brouwers: Conceptualization, Methodology, Software, Writing - original draft. Bianca Cox: Conceptualization, Methodology, Data curation, Writing - original draft. Astrid Van Wilder: Writing - review \& editing. Fien Claessens: Writing - review \& editing. Luk Bruyneel: Conceptualization, Writing - review \& editing. Dirk De Ridder: Conceptualization, Writing - review \& editing, Supervision. Kristof Eeckloo: Writing - review \& editing, Supervision. Kris Vanhaecht: Conceptualization, Writing - original draft, Supervision.

\section{Funding}

Jonas Brouwers received an unconditional grant from Sawtooth Software for using Sawtooth Software Lighthouse Studio and Sawtooth Software Hosting. This work was supported by the KU Leuven chair 'Zorgnet-Icuro: Future of Hospital quality' established on $21 / 10 / 2019$. This research received no other specific grant from any funding agency in the public, commercial or not-for-profit sectors. 


\section{Supplementary materials}

Supplementary material associated with this article can be found, in the online version, at doi:10.1016/j.healthpol.2021.10.008.

\section{References}

[1] Klazinga N. Re-engineering trust: the adoption and adaption of four models for external quality assurance of health care services in western European health care systems. Int J Qual Heal Care 2000;12:183-9. doi:10.1093/intahc/12.3.183.

[2] Heaton C. External peer review in Europe: an overview from the ExPeRT Project. Int J Qual Heal Care 2000;12:177-82. doi:10.1093/intqhc/12.3.177.

[3] Robert G, Sarre S, Maben J, Griffiths P, Chable R. Exploring the sustainability of quality improvement interventions in healthcare organisations: a multiple methods study of the 10-year impact of the "Productive Ward: releasing Time to Care" programme in English acute hospitals. BMJ Qual Saf 2020;29:31-40. doi:10.1136/bmjqs-2019-009457.

[4] Shaw CD. External quality mechanisms for health care: summary of the ExPeRT project on visitatie, accreditation, EFQM and ISO assessment in European Union countries. Int J Qual Heal Care 2000;12:169-75. doi:10.1093/intqhc/12. 3.169

[5] Rechel B, Maresso A, Sagan A, Hernández-Quevedo C, Williams G, Richardson E, et al. Organization and financing of public health services in Europe: Country reports 2018;49.

[6] OECD, WHO Improving healthcare quality in europe. OECD; 2019. doi:101787/ b11a6e8f-en.

[7] Tello JE, Barbazza E, Waddell K. Review of 128 quality of care mechanisms: a framework and mapping for health system stewards. Health Policy (New York) 2020;124:12-24. doi:10.1016/j.healthpol.2019.11.006.

[8] Pross C, Geissler A, Measuring Busse R. Reporting, and Rewarding Quality of Care in 5 Nations: 5 Policy Levers to Enhance Hospital Quality Accountability. Milbank Q 2017;95:136-83. doi:10.1111/1468-0009.12248.

[9] Greenfield D, Braithwaite J. Health sector accreditation research: a systematic review, 20. Narnia; 2008. doi:10.1093/intqhc/mzn005.

[10] Mumford V, Forde K, Greenfield D, Hinchcliff R, Braithwaite J, V M, et al. Health services accreditation: what is the evidence that the benefits justify the costs? Int J Qual Heal Care 2013;25:606-20. doi:10.1093/intqhc/mzt059.

[11] European Commision -Expert Group on Health Systems Performance Assessment. So what? - Strategies across Europe to assess quality of care. 2016. https://doi.org/10.2875/03667.

[12] Blumenthal DM, Valsdottir LR, Zhao Y, Shen C, Kirtane AJ, Pinto DS, et al. A Survey of Interventional Cardiologists' Attitudes and Beliefs About Public Reporting of Percutaneous Coronary Intervention. JAMA Cardiol 2018;3:629. doi:10.1001/jamacardio.2018.1095.

[13] Mannion R, Braithwaite J. Unintended consequences of performance measurement in healthcare: 20 salutary lessons from the English National Health Service. Intern Med J 2012;42:569-74. doi:10.1111/j.1445-5994.2012.02766.x.

[14] de Bree M, Stoopendaal A. De- and Recoupling and Public Regulation. Organ Stud 2020;41:599-620. doi:10.1177/0170840618800115.

[15] Leistikow I, Bal RA. Resilience and regulation, an odd couple? Consequences of Safety-II on governmental regulation of healthcare quality. BMJ Qual Saf 2020;29:869-72. doi:10.1136/bmjqs-2019-010610.

[16] Wadhera RK, O’Brien CW, Joynt Maddox KE, Ho KKL, Pinto DS, Resnic FS, et al. Public Reporting of Percutaneous Coronary Intervention Outcomes: institutional Costs and Physician Burden. J Am Coll Cardiol 2019;73:2604-8. doi:10.1016/j.jacc.2019.03.014.

[17] Alkhenizan A, Shaw C. The attitude of health care professionals towards accreditation: a systematic review of the literature. J Fam Community Med 2012;19:74. doi:10.4103/2230-8229.98281.

[18] Kakemam E, Rajabi MR, Raeissi P, Ehlers LH. Attitudes towards accreditation and quality improvement activities among hospital employees in Iran: a quantitative study. J Multidiscip Healthc 2020;13:799-807. doi:10.2147/JMDH. S263811.

[19] Jha AK. Accreditation, Quality, and Making Hospital Care Better. JAMA - J Am Med Assoc 2018. doi:10.1001/jama.2018.18810.

[20] Prang KH, Canaway R, Bismark M, Dunt D, Miller JA, Kelaher M. Public performance reporting and hospital choice: a cross-sectional study of patients undergoing cancer surgery in the Australian private healthcare sector. BMJ Open 2018. doi:10.1136/bmjopen-2017-020644.

[21] Greenfield D, Debono D, Hogden A, Hinchcliff R, Mumford V, Pawsey M, et al. Examining challenges to reliability of health service accreditation during a period of healthcare reform in Australia. J Heal Organ Manag 2015;29:912-24. doi:10.1108/JHOM-02-2015-0034.

[22] Griffith JR. Is It Time to Abandon Hospital Accreditation? Am J Med Qual 2018;33:30-6. doi:10.1177/1062860617707578.

[23] Braithwaite J, Ludlow K, Churruca K, James W, Herkes J, McPherson E, et al. Systems transformation: learning from change in 60 countries. J Health Organ Manag 2019;34:237-53. doi:10.1108/JHOM-01-2019-0018.

[24] Sibert K. When the Joint Commission is at the hospital, leave. MedPage Today 2014

[25] Ellis LA, Nicolaisen A, Bie Bogh S, Churruca K, Braithwaite J, Von Plessen C. Accreditation as a management tool: a national survey of hospital managers' perceptions and use of a mandatory accreditation program in Denmark. BMC Health Serv Res 2020;20:1-9. doi:10.1186/s12913-020-05177-7.
[26] Ehlers LH, Jensen MB, Simonsen KB, Rasmussen GS, Braithwaite J. Attitudes towards accreditation among hospital employees in Denmark: a crosssectional survey. Int J Qual Heal Care 2017;29:693-8. doi:10.1093/intqhe/ mzx090.

[27] Ryan M, Farrar S. Using conjoint analysis to elicit preferences for health care. Br Med J 2000;320:1530-3. doi:10.1136/bmj.320.7248.1530.

[28] Ryan M. Discrete choice experiments in health care. Br Med J 2004;328:360-1. doi:10.1136/bmj.328.7436.360.

[29] Ryan M, Scott DA, Reeves C, Bate A, Van Teijlingen ER, Russell EM, et al. Eliciting public preferences for healthcare: a systematic review of techniques. Health Technol Assess (Rockv) 2001;5. doi:10.3310/hta5050.

[30] Salloum RG, Shenkman EA, Louviere JJ, Chambers DA. Application of discrete choice experiments to enhance stakeholder engagement as a strategy for advancing implementation: a systematic review. Implement Sci 2017;12:1-12. doi:10.1186/s13012-017-0675-8.

[31] Van Wilder A, Bruyneel L, De Ridder D, Seys D, Brouwers J, Claessens F, et al. Is a hospital quality policy based on a triad of accreditation, public reporting and inspection evidence-based? A narrative review. Int J Qual Heal Care 2021;33. doi:10.1093/intqhc/mzab085

[32] Bahrampour M, Byrnes J, Norman R, Scuffham PA, Downes M. Discrete choice experiments to generate utility values for multi-attribute utility instruments: a systematic review of methods. Eur J Heal Econ 2020:1-10. doi:10.1007/ s10198-020-01189-6.

[33] Soekhai V, de Bekker-Grob EW, Ellis AR, Vass CM. Discrete Choice Experiments in Health Economics: past, Present and Future. Pharmacoeconomics 2019;37:201-26. doi:10.1007/s40273-018-0734-2.

[34] Clark MD, Determann D, Petrou S, Moro D, de Bekker-Grob EW. Discrete Choice Experiments in Health Economics: a Review of the Literature. Pharmacoeconomics 2014. doi: 10.1007/s40273-014-0170-X.

[35] De Bekker-Grob EW, Ryan M, Gerard K. Discrete choice experiments in health economics: a review of the literature. Health Econ 2012;21:145-72. doi:10. 1002/hec.1697.

[36] Cleemput I, Devriese S, Kohn L, Westhovens R. A multi-criteria decision approach for ranking unmet needs in healthcare. Health Policy (New York) 2018;122:878-84. doi:10.1016/j.healthpol.2018.06.010.

[37] Peters Y, Siersema PD. Public Preferences and Predicted Uptake for Esophageal Cancer Screening Strategies: a Labeled Discrete Choice Experiment. Clin Transl Gastroenterol 2020;11:e00260. doi:10.14309/ctg.0000000000000260.

[38] Janssen EM, Segal JB, Bridges JFP. A Framework for Instrument Development of a Choice Experiment: an Application to Type 2 Diabetes. Patient 2016;9:46579. doi:10.1007/s40271-016-0170-3.

[39] Brown A, Dickinson H, Kelaher M. Governing the quality and safety of healthcare: a conceptual framework. Soc Sci Med 2018;202:99-107. doi:10.1016/j. socscimed.2018.02.020.

[40] Jones B, Vaux E, Olsson-Brown A. How to get started in quality improvement BMJ 2019;364:k5408. doi:10.1136/bmj.k5437.

[41] Eu W.H., Busse R., Klazinga N., Panteli D., Quentin W. Health Policy Series No. 53 The editors Improving healthcare quality in Europe Characteristics, effectiveness and implementation of different strategies. 2019.

[42] Greenfield D, Hinchcliff R, Banks M, Mumford V, Hogden A, Debono D, et al. Analysing 'big picture' policy reform mechanisms: the Australian health service safety and quality accreditation scheme. Heal Expect 2015;18:3110-22. doi:10. 1111/hex.12300.

[43] Hinchcliff R, Greenfield D, Moldovan M, Westbrook JI, Pawsey M, Mumford V, et al. Narrative synthesis of health service accreditation literature. BMJ Qual Saf 2012;21:979-91. doi:10.1136/bmjqs-2012-000852.

[44] OECD Caring for quality in health. OECD; 2017. doi:101787/9789264267787-en.

[45] Hauber AB, González JM, Groothuis-Oudshoorn CGM, Prior T, Marshall DA, Cunningham C, et al. Statistical Methods for the Analysis of Discrete Choice Experiments: a Report of the ISPOR Conjoint Analysis Good Research Practices Task Force. Value Heal 2016;19:300-15. doi:10.1016/j.jval.2016. 04.004 .

[46] Steiner M, Meißner M. A user's guide to the galaxy of conjoint analysis and compositional preference measurement. Mark Zeitschrift Fur Forsch Und Prax 2018;40:3-25. doi:10.15358/0344-1369-2018-2-3.

[47] Chrzan K. Orme B. An Overview and Comparison of Design Strategies for Choice-Based Conjoint Analysis. In: Sawtooth Softw. Conf. Proc; 2000 p. $161-75$

[48] Bridges JFP, Hauber AB, Marshall D, Lloyd A, Prosser LA, Regier DA, et al. Conjoint Analysis Applications in Health-A Checklist: a Report of the ISPOR Good Research Practices for Conjoint Analysis Task Force. Value Heal 2011;14:40313. doi:10.1016/j.jval.2010.11.013.

[49] Lancsar E, Louviere J. Conducting discrete choice experiments to inform healthcare decision making: a user's guide. Pharmacoeconomics 2008;26:66177. doi:10.2165/00019053-200826080-00004.

[50] Marshall D, Bridges JFP, Hauber B, Cameron R, Donnalley L, Fyie K, et al. Conjoint analysis applications in health-how are studies being designed and reported?: an update on current practice in the published literature between 2005 and 2008. Patient 2010;3:249-56. doi:10.2165/ 11539650-000000000-00000.

[51] Orme B. The CBC / HB System for Hierarchical Bayes Estimation Version 5.0 Technical Paper. Sawtooth Softw Tech Pap Ser 2009;5.

[52] McCarthy SE, Jabakhanji SB, Martin J, Flynn MA, Sørensen J. Reporting standards, outcomes and costs of quality improvement studies in Ireland: a scoping review. BMJ Open Qual 2021;10:e001319. doi:10.1136/bmjoq-2020001319. 
[53] Lachman P, Batalden P, Vanhaecht K. A multidimensional quality model: an opportunity for patients, their kin, healthcare providers and professionals in the new COVID-19 period. F1000Res 2020;9:1140. doi:10.12688/f1000research. 26368.1.

[54] Uggerby C, Kristensen S, MacKenhauer J, Knudsen SV, Bartels P, Johnsen SP, et al. From accreditation to quality improvement - The Danish National Quality Programme. Int J Qual Heal Care 2021;33:1-3. doi:10.1093/intqhc/mzab071.

[55] Flodgren G, Gonçalves-Bradley DC, Pomey MP. External inspection of compliance with standards for improved healthcare outcomes. Cochrane Database Syst Rev 2016 2016. doi:10.1002/14651858.CD008992.pub3.

[56] Shaw G. National clinical programmes in the Republic of Ireland: a qualitative study of acute hospitals. J Res Nurs 2020;25:421-40. doi:10.1177| 1744987119893014

[57] Wells S, Tamir O, Gray J, Naidoo D, Bekhit M, Goldmann D. Are quality improvement collaboratives effective? A systematic review. BMJ Qual Saf 2018;27:226-40. doi:10.1136/bmjqs-2017-006926.

[58] Pham JC, Girard T, Pronovost PJ. What to do with healthcare Incident Reporting Systems. J Public Health Res 2013;2:27. doi:10.4081/jphr.2013.e27.

[59] Milligan C, Allin S, Farr M, Farmanova E, Peckham A, Byrd J, et al. Mandatory reporting legislation in Canada: improving systems for patient safety? Heal Econ Policy Law 2021;16:355-70. doi:10.1017/S1744133121000050.

[60] Kassim PNJ. Mandatory incident reporting through legislative framework: towards enhancing patient safety culture in healthcare settings. J Humanit Lang Cult Bus 2017;1:181-9.

[61] Fung CH, Lim YW, Mattke S, Damberg C, Shekelle PG. Systematic review: the evidence that publishing patient care performance data improves quality of care. Ann Intern Med 2008;148:111-23. doi:10.7326/ 0003-4819-148-2-200801150-00006.

[62] National academy of sciences. Rewarding provider performance: aligning incentives in Medicare. 2007. https://doi.org/10.17226/11723.

[63] Agency for Healthcare Research and Quality. Public Information as Part of a Multi- pronged strategy n.d. 2021

[64] Shahian DM, Jacobs JP, Badhwar V, D’Agostino RS, Bavaria JE, Prager RL. Risk Aversion and Public Reporting. Part 1: observations From Cardiac Surgery and Interventional Cardiology. Ann Thorac Surg 2017;104:2093-101. doi:10.1016/j. athoracsur.2017.06.077.

[65] Shahian DM, Jacobs JP, Badhwar V, D’Agostino RS, Bavaria JE, Prager RL. Risk Aversion and Public Reporting. Part 2: mitigation Strategies. Ann Thorac Surg 2017;104:2102-10. doi:10.1016/j.athoracsur.2017.06.076.

[66] Metcalfe D, Rios Diaz AJ, Olufajo OA, Massa MS, Ketelaar NABM, Flottorp SA, et al. Impact of public release of performance data on the behaviour of healthcare consumers and providers. Cochrane Database Syst Rev 20182018. doi:10.1002/14651858.CD004538.pub3.
[67] Emmert M., Taheri-Zadeh F., Kolb B., Sander U. Public reporting of hospital quality shows inconsistent ranking results. Health Policy (New York) 2017;121:17-26. https://doi.org/10.1016/j.healthpol.2016.11.004.

[68] Balik B, Conway J, Zipperer L, Watson J. Achieving an Exceptional Patient and Family Experience of Inpatient Hospital Care. IHI Innov Ser White Pap 2011:1-34.

[69] Mirzoev T, Kane S. Key strategies to improve systems for managing patient complaints within health facilities-what can we learn from the existing literature? Glob Health Action 2018;11. doi:10.1080/16549716.2018.1458938.

[70] Schuldt J, Doktor A, Lichters M, Vogt B, Robra BP. Insurees' preferences in hospital choice-A population-based study. Health Policy (New York) 2017;121:1040-6. doi:10.1016/j.healthpol.2017.08.004.

[71] Wu L, Wu Y, Zou S, Sun C, Chen J, Li X, et al. Eliciting women's preference for prenatal testing in China: a discrete choice experiment. BMC Pregnancy Childbirth 2020;20:604. doi:10.1186/s12884-020-03270-7.

[72] Ledent E, Gabutti G, de Bekker-Grob EW, Alcázar Zambrano JL, Campins Martí M, Del Hierro Gurruchaga MT, et al. Attributes influencing parental decision-making to receive the Tdap vaccine to reduce the risk of pertussis transmission to their newborn-outcome of a cross-sectional conjoint experiment in Spain and Italy. Hum Vaccines Immunother 2019;15:1080-91. doi:10.1080/21645515.2019.1571890.

[73] Patterson JA, Holdford DA, Harpe SE. Patient preferences for objective quality metrics during community pharmacy selection: a discrete choice experiment. Res Soc Adm Pharm 2019;15:641-9. doi:10.1016/j.sapharm.2018.08.002.

[74] Vallejo-Torres L, Melnychuk M, Vindrola-Padros C, Aitchison M, Clarke CS, Fulop NJ, et al. Discrete-choice experiment to analyse preferences for centralizing specialist cancer surgery services. Br J Surg 2018;105:587-96. doi:10.1002/bjs. 10761.

[75] Scuffham PA, Whitty JA, Taylor M, Saxby RC. Health system choice: a pilot discrete-choice experiment eliciting the preferences of British and Australian citizens. Appl Health Econ Health Policy 2010;8:89-97. doi:10.2165/ 11531170-000000000-00000.

[76] Baltussen R, Niessen L. Priority setting of health interventions: the need for multi-criteria decision analysis. Cost Eff Resour Alloc 2006;4:14. doi:10.1186/ 1478-7547-4-14.

[77] Pignone MP, Brenner AT, Hawley S, Sheridan SL, Lewis CL, Jonas DE, et al. Conjoint analysis versus rating and ranking for values elicitation and clarification in colorectal cancer screening. J Gen Intern Med 2012. doi:10.1007/ s11606-011-1837-z.

[78] Johnson FR, Lancsar E, Marshall D, Kilambi V, Mühlbacher A, Regier DA, et al. Constructing experimental designs for discrete-choice experiments: report of the ISPOR conjoint analysis experimental design good research practices task force. Value Heal 2013. doi:10.1016/j.jval.2012.08.2223. 